УДК 372.862

\title{
OPTIMIZATION OF THE PROCESS OF LABORATORY RESEARCH ON THE BASIS OF THE SYSTEM APPROACH
}

V.Samsonov

National University of Food Technologies

A. Sil'vestrov, O. Skrypnyk

National Technical University of Ukraine "Igor Sikorsky Kyiv Polytechnic

Institute”

\begin{tabular}{|c|c|}
\hline Key & \multirow{17}{*}{$\begin{array}{l}\text { This article viewed the problem of improving the efficiency } \\
\text { of existing laboratory tests of general engineering discip- } \\
\text { lines characterized by outdated physical and mathematical } \\
\text { basis. This reduces the interest of the students to a deeper } \\
\text { analysis of objects and processes. The authors believe that } \\
\text { the facilities operate within the existing laws and, therefore, } \\
\text { they are not interesting for the students. Therefore, expe- } \\
\text { rimental research should be aimed at clarifying the mathe- } \\
\text { matical model of the object under study based on a } \\
\text { systematic approach in which research results are evaluated } \\
\text { by key indicators of quality of educational resources, such as } \\
\text { performance, validity, reliability and manufacturability. A } \\
\text { range of estimates, which are set by the developers of the } \\
\text { course, are introduced for the success criteria. By } \\
\text { manufacturability we understand the degree of automation } \\
\text { of the research results processing. The process of laboratory } \\
\text { studies optimization is illustrated on the specific example. }\end{array}$} \\
\hline Laboratory & \\
\hline Syst & \\
\hline Quali & \\
\hline methods realization & \\
\hline Optimization & \\
\hline Experimental design & \\
\hline Performance & \\
\hline Manufacturab & \\
\hline Arti & \\
\hline Received 17.05 & \\
\hline Received in revised form & \\
\hline & \\
\hline Accepted 20 & \\
\hline Corresponding auth & \\
\hline sonov & \\
\hline & \\
\hline
\end{tabular}

DOI: $10.24263 / 2225-2924-2017-23-4-5$

\section{ОПТИМІЗАЦІЯ ПРОЦЕСУ ЛАБОРАТОРНИХ ДОСЛІДЖЕНЬ НА ОСНОВІ СИСТЕМНОГО ПІДХОДУ}

\section{B.В. Самсонов}

Національний університет харчових технологій

А.М. Сільвестров, О.М. Скринник

Національний технічний університет Украӥни «Київський політехнічний інститут імені Ігоря Сікорського»

У статті розглянуто проблему підвищення ефективності існуючих лабораторних досліджень загальноінженерних дисииплін, які характеризуються застарілою фізико-математичною основою, що знижує інтерес у студентів до більш глибокого аналізу об'єктів і прочесів. Доведено, що експериментальні дослідження повинні мати своєю метою уточнення математичної моделі об 'єкта, що досліджується, на основі системного підходу, за якого результати досліджень оцінюються основними показниками якості освітніх ресурсів, таких як успішність, валідність, надійність і технологічність. Для 
критерію успішності введено діапазон оцінок, які встановлюються розробником курсу. Під технологічністю мається на увазі ступінь автоматизаиії обробки результатів дослідження. Прочес оптимізачії лабораторних досліджень проілюстровано на конкретному прикладі.

Ключові слова: лабораторні дослідження, системній підхід, якість методики проведення дослідження, оптимізація, планування експерименту, успішність, технологічність.

Постановка проблеми. Електротехнічні дисципліни, такі як «Електротехніка», «Теорія електричних кіл», «Електроніка» та ін., що відносяться до загально-інженерних, характеризуються майже незмінною у часі фізико-математичною основою. Це отримані сторіччя назад закони Кулона-Кевіндеша, Ампера, Ома, Кірхгофа, Фарадея, Джоуля-Ленца та ін., які можна трактувати як спрощені рівняння Максвела електромагнітного поля для відповідного середовища, що має конкретні геометричні та фізичні властивості. Така стабільність у часі і фундаментальність цих законів стосовно процесу викладання і засвоєння студентами є як позитивною, так і негативною.

Позитив полягає у чіткій (на перший погляд) обгрунтованості процесів i об'єктів електротехнічної природи. Це не повинно викликати сумнівів щодо істинності їх фізико-математичних моделей. Віра в їх істинність повинна грунтуватися на практичному підтвердженні, яке отримують студенти на лабораторних роботах. За відповідної точності приладів має місце близькість теоретичних і експериментальних результатів. I предмет засвоюється студентами як абсолютно-конкретний з повністю визначеними властивостями об'єкта.

Негатив полягає у відсутності інтересу до більш глибокого аналізу об'єктів і процесів, що вивчаються, до творчого пошукового підходу: студенту немає необхідності сумніватися у можливій неточності, а інколи і некоректності фізико-математичних моделей об'єктів і процесів, що вивчаються. Дійсно, навіщо щось удосконалювати, якщо і так, на перший погляд, все гаразд: $\epsilon$ закони, є об'єкти, в яких вони діють, і немає проблем щодо їх аналізу і додаткових досліджень. Це гальмує розвиток творчих здібностей у студентів, а інколи і у викладачів, які викладають ці предмети. Все, що завершене, мертве $\mathrm{i}$, як наслідок, нецікаве. Можливо тому успішність, яка безпосередньо пов'язана з зацікавленістю, часто буває досить низькою.

У засвоєнні того чи іншого предмета, з метою зацікавленості студента, повинна лежати інтрига, побудована на невідповідності реальних процесів їх ідеалізованій моделі. Експериментальні дослідження (тобто лабораторні роботи) повинні мати своєю метою уточнення математичної моделі процесу чи об'єкта, що досліджується. Під об'єктом розуміють конкретний електротехнічний прилад, апарат або пристрій, під процесом - змінні стану і параметри об'єкта: струми, напруги, опори, індуктивності, ємності тощо.

Застарілість, з одного боку, стендового обладнання лабораторних робіт 3 електротехнічних дисциплін, ручна обробка результатів експериментів 3 побудовою одномірних графіків, з іншого - досконалі методи, алгоритми i програми для ЕОМ у деяких випадках привели до того, що лабораторні 
роботи взагалі виконуються віртуально. При цьому втрачається важлива частина навчання - вміння працювати з реальними електротехнічними установками та приладами, які мають свої особливості.

Разом $з$ тим гріх не скористатися високоефективними сучасними методами планування експерименту, автоматизації (якщо є можливість) проведення та оптимальної обробки його результатів на комп'ютері. Завдяки методам оптимального планування та обробки даних на ЕОМ з'являється можливість зробити лабораторні роботи більш цікавими, більш коректними і глибокими та отримати статистично-обгрунтовані результати.

3'являється можливість у повній мірі використати могутній апарат сучасної теорії систем, системний підхід, в основу якого покладено поняття фізикоматематичної моделі об'єкту чи процесу, що досліджується, методів експериментальної перевірки структури й уточнення параметрів. Лабораторні роботи за такої методики являють зворотній зв'язок у процесі пізнання об'єкта чи процесу, що досліджується, який направлено на отримання апостеріорної моделі, отриманої як уточнення апріорної теоретичної.

За такої постановки лабораторних робіт у студентів з'являється інтерес до наукових досліджень, які б уточнювали теоретичні положення стосовно до опису реальних об'єктів. Виробляються також навички до більш відповідального ставлення до апріорних моделей і методик натурних випробувань відповідних виробів виробництва 3 метою отримання об'єктивних характеристик цих виробів по апостеріорним моделям.

Мета дослідження: оптимізація процесу лабораторних досліджень на основі системного підходу для забезпечення високої якості методики проведення лабораторних досліджень і навчально-методичних матеріалів в умовах масовості освіти і швидкого старіння інформації, що обумовлює необхідність моніторингу якості освітніх ресурсів.

Викладення основних результатів дослідження. Основними показниками якості освітніх ресурсів є успішність, валідність, надійність і технологічність, використання яких стосовно завдань моніторингу якості освітніх ресурсів вимагає системного підходу. Так, жоден із показників окремо не дає змоги отримати об'єктивну оцінку якості освітніх ресурсів.

Стосовно завдання моніторингу доцільно розглянути якість освітнього ресурсу у вигляді двох критеріїв: успішність і технологічність.

Високий рівень підготовки учнів $є$ основним критерієм усіх складових освітньої системи, в тому числі і методики проведення лабораторних досліджень. Основною загальноприйнятою мірою якості навчальної діяльності $\epsilon$ успішність. Якщо ж діапазон успішності учнів визначається внутрішніми вимогами освітнього закладу, то вимоги до успішності за методикою проведення лабораторних досліджень доцільно встановлювати експертним методом для кожного дослідження окремо з необхідним рівнем деталізації. Отже, введено діапазон успішності по освітньому курсу $\varphi_{1}, \varphi_{1} \in\left[\varphi_{\min }, \varphi_{\max }\right]$, де $\varphi_{\min } \epsilon$ мінімально допустиме значення успішності, $\varphi_{\max }$ - максимально допустиме значення успішності, яке встановлюється розробником курсу. Шкала первинних балів для визначення успішності задається у вигляді 
$\Delta y=\left\{\Delta y_{\min }, \Delta y_{\max }\right\}$, де $\Delta y_{\min }-$ мінімально допустима задовільна оцінка, $\Delta y_{\max }$ - максимально можлива оцінка. При цьому локальний критерій $Q_{U_{s p}}$ має вигляд [1]:

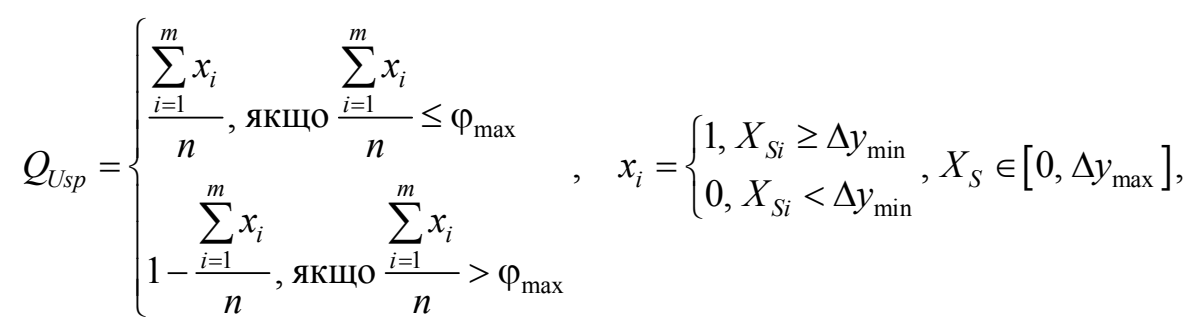

де $X_{S}$ - первинні бали учнів; $n-$ кількість учнів.

Під технологічністю мається на увазі ступінь автоматизації обробки результатів дослідження. Згідно з результатами досліджень [2] індивідуалізація навчання в умовах масової освіти можлива тільки при використанні інформаційних технологій у навчальному процесі, тому що застосування інтерактивних підручників, мультимедійних тренажерів, автоматизованих засобів контролю й самоконтролю забезпечує індивідуальні траєкторії і темп навчання, підвищує ефективність навчального процесу та об'єктивність оцінки рівня підготовки учнів [3]. Найбільш ефективним підходом до організації навчального процесу є скорочення часу безпосередньої взаємодії викладача зі студентом при вивченні освітніх ресурсів 3 низьким рівнем засвоєння при одночасному збільшенні часу безпосередньої взаємодії викладача зі студентом в міру зростання необхідного рівня засвоєння завдань.

Стосовно задачі моніторингу якості освітніх ресурсів ранжування рівнів засвоєння навчальних цілей виконується 3 урахуванням зростання рівня засвоєння $\alpha$ від 1 до 8 [4].

Рівень засвоєння освітніх ресурсів встановлюється експертним методом на етапі впровадження курсу. Нормований коефіцієнт засвоєння освітніх ресурсів $k_{\mathrm{i}}^{\alpha}=\frac{\alpha_{i}}{\alpha_{\max }}$. Локальний критерій технологічності $Q_{T e h}$ :

$$
Q_{T e h}=\frac{\sum_{i=0}^{j} k_{i}^{T} \cdot k_{i}^{\alpha}}{j}, \quad k_{i}^{T}=\frac{t_{i}}{t_{\max }}
$$

де $k_{i}^{T}$ - коефіцієнт технологічності і-го освітнього ресурсу, $k_{i}^{T} \in[0 \ldots 1] ; k_{i}^{\alpha}-$ коефіцієнт засвоєння і-го завдання; $t_{i}-$ ступінь технологічності освітніх ресурсів, встановлювана експертним методом за абсолютною бальною шкалою залежно від способу організації зворотного зв'язку при контролі і самоконтролі.

Сутність системного підходу,як інструмента оптимізації цих критеріїв, на відміну від традиційного, перш за все полягає у використанні й уточненні за даними експерименту об'єкта дослідження та його математичної моделі. Для 
побудови моделі об'єкта потрібно володіти достатньою інформацією про нього. На етапі формалізації завдання будується математична модель 3 використанням законів 3 предметної області даного об'єкта, невідомі параметри моделі знаходяться за допомогою алгоритмів параметричної ідентифікації.

Доцільно розглянути і порівняти 3 традиційним підходом технологію проведення досліджень, яка використовує системний підхід. Як приклад, взято лабораторну роботу «Визначення електричного опору $R$ резистора за допомогою вольтметра і амперметра». У традиційній постановці, на основі загально прийнятого закону Ома, оцінка $\widehat{R}$ опору $R$ визначається як відношення показів $U$ вольтметра до $I$ амперметра. Тут не враховано фундаментальну властивість об'єктів реального світу, де все 3 усім взаємопов'язано $i$, як наслідок $R$ залежить від $I$.

У постановці, побудованій на основі системного підходу, шляхом врахування фундаментальних положень фізики, встановлюється апріорна (теоретична) модель резистора як об'єкта, в якому закон Ома $U=R \cdot I, R=\mathrm{const}$ суперечить закону Джоуля-Ленца $P=I^{2} \cdot R$, де $P$ - потужність, і рівнянням термодинаміки:

$$
d Q=c m d \theta^{0}+K_{T V} S_{O h} \cdot \Delta \theta^{0} d t,
$$

де $d Q$ - приріст теплоти $Q ; \theta^{0}, c, m, K_{T v}, S_{O h}$ - параметри резистора, відповідно, температура, теплоємність, маса, коефіцієнт тепловіддачі, площа охолодження резистора.

Швидкість зміни $Q \in$ потужність $P$, яку отримаємо, якщо продиференціювати вираз (3):

$$
\frac{d Q}{d t}=P=I^{2} \cdot R\left(\theta^{0}\right)=c m \frac{d \theta^{0}}{d t}+K_{T v} \cdot S_{O h} \cdot \Delta \theta^{0}
$$

Якщо для спрощення прийняти, що потужність $P$ незмінна, то в усталеному режимі $\frac{d \theta^{0}}{d t}$ дорівнюватиме нулю, а

$$
P=I^{2} \cdot R\left(\theta_{\infty}^{0}\right)=K_{T v} \cdot S_{O h} \cdot \Delta \theta_{\infty}^{0},
$$

де $\Delta \theta_{\infty}^{0}=\theta_{\infty}^{0}-\theta_{0}^{0}$.

Тоді вираз (3) набуває вигляду:

$$
\tau_{m} \frac{d \Delta \theta^{0}}{d t}+\Delta \theta^{0}=\Delta \theta_{\infty}^{0}
$$

де $\tau_{m} \frac{c m}{K_{T v} \cdot S_{O h}}$ - теплова стала часу резистора, $\Delta \theta^{0}=\theta^{0}(t)-\theta_{0}^{0}, \frac{d \Delta \theta^{0}}{d t}=\frac{d \theta^{0}}{d t}$.

Питома провідність резистора залежить від коефіцієнта $\beta$ вільного пробігу електрона, який для металів зменшується при збільшенні температури $\theta^{0}$ внаслідок збільшення протидії напрямленому руху тепловим хаотичним. Тобто 


$$
\beta=\beta\left(\theta^{0}\right) .
$$

Тоді опір $R$ буде функцією $\theta^{0}$. Для відносно малих змін $\Delta \theta^{0}$ в межах $0 \div 100^{\circ} \mathrm{C}$ ця залежність майже лінійна:

$$
R\left(\theta^{0}\right) \cong R\left(\theta_{0}^{0}\right) \cdot\left[1+\alpha \Delta \theta^{0}\right]
$$

де $\alpha-$ температурний коефіцієнт опору.

Для потужних резисторів, реостатів теплова стала часу може бути значною. Нагрів провідника резистора згідно з (6) відбувається за експоненціальним законом:

$$
\theta^{0}(t)=\theta^{0}(0)+\Delta \theta^{0}(t)=\theta^{0}(0)+\Delta \theta_{\infty}^{0}\left(1-e^{\frac{-t}{\tau_{m}}}\right) .
$$

Відповідно $R\left(\theta^{0}(t)\right)$, з урахуванням (8) і (9), буде змінюватись у часі, змінюючи за тією ж експонентою свій опір від $R\left(\theta_{0}^{0}\right)$ до $R\left(\theta_{\infty}^{0}\right)$ (рис. 1$)$ :

$$
R\left(\theta^{0}(t)\right)=R\left(\theta^{0}(0)\right) \cdot\left[1+\alpha \Delta \theta^{0}(t)\right]=R\left(\theta^{0}(0)\right) \cdot\left[1+\alpha \Delta \theta_{\infty}^{0}\left(1-e^{\frac{t}{\tau_{m}}}\right)\right] .
$$

Рис. 1. Графік $R\left(\theta^{0}(t)\right)$

Залежно від динаміки зміни напруги $U$, коефіцієнтів $m, K_{T v}, S_{O h}, c, \alpha$, приросту $\Delta \theta^{0}$ залежність $R\left(I^{2}\left(\theta^{0}(t)\right)\right)$ може бути як суттєвою, так і несуттєвою. Відповідно, резистор може розглядатися як безінерційний, так і інерційний, як лінійний елемент зі сталим опором $R$, так і нелінійний, де $R\left(I^{2}\right)$.

Визначимо аналітичну залежність $R(I)$ в усталеному режимі. 3 рівняння (4) при $\frac{d \theta^{0}}{d t}=0$ і $t \rightarrow \infty$ отримаємо:

$$
I^{2} R\left(\theta_{\infty}^{0}\right)=K_{T v} \cdot S_{O h} \cdot \Delta \theta_{\infty}^{0} .
$$


Знайдемо звідси $\Delta \theta_{\infty}^{0}$ і підставимо в рівняння (8):

$$
R\left(\theta_{\infty}^{0}\right) \cong R\left(\theta_{0}^{0}\right) \cdot\left[1+\alpha \frac{R\left(\theta_{\infty}^{0}\right)}{K_{T V} \cdot S_{O h}} \cdot I^{2}\right] .
$$

Або враховуючи, що $\alpha \frac{R\left(\theta_{0}^{0}\right)}{K_{T v} \cdot S_{O h}} \cdot I^{2}<<1$ з розкладання (12) у ряд замість (12) наближено маємо:

$$
R\left(\theta_{\infty}^{0}\right)=R\left(\theta_{0}^{0}\right)\left[1+\eta \cdot I^{2}\right],
$$

де $\eta$ - параметр резистора, який визначає вплив струму $I$ на опір $R$,

$$
\eta=\alpha \frac{R\left(\theta_{0}^{0}\right)}{K_{T v} \cdot S_{O h}} .
$$

Параметр $\eta$ пропорційний $\alpha$ і зворотно пропорційний $K_{T v} \cdot S_{O h}$. Залежно від величини $\eta$ і $I^{2}$, а також точності вимірювань, резистор слід розглядати як лінійний чи нелінійний елемент.

Далі, розглядаючи резистор як нелінійний об'єкт, на основі методів математичної статистики будується оптимальний план експерименту.

Вольт-амперні характеристики лінійного

$$
U_{L}=R_{s t \text { max }} \cdot I=\frac{U_{\max }}{I_{\max }} \cdot I
$$

і нелінійного резистора

$$
U_{N L}=\left(\beta_{0}+\beta_{1} I^{2}\right) \cdot I
$$

представлені на рис. 2.

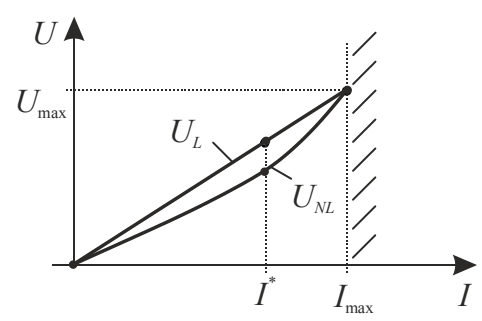

Рис. 2. Вольт-амперні характеристики резистора

Якщо від рівняння (13) відняти (14) і підставити $R_{s t \text { max }}=\beta_{0}+\beta_{1} I_{\max }^{2}$ $R_{\text {st.max }}$, отримаємо:

$$
U_{L}-U_{N L}=\beta_{1}\left(I_{\max }^{2}-I^{2}\right) \cdot I .
$$

Оптимальне значення $I^{*}$, за якого різниця між $U_{J}$ i $U_{H л}(15)$ максимальна, потрібно визначити за умови: 


$$
\frac{d}{d I}\left(U_{L}-U_{N L}\right)=\beta_{1} I_{\max }^{2}-3 \beta_{1} I^{* 2}=0 \Rightarrow I^{*}=I_{\max } / \sqrt{3}
$$

Таким чином отримують дві точки оптимального плану експерименту: $I^{*}$ i $I_{\max }$. Із виразів (15), (16) визначають $\beta_{0}$ та $\beta_{1}$ :

$$
\begin{gathered}
\beta_{1}=\frac{U_{\max } \cdot\left(I^{*} / I_{\max }\right)-U^{*}{ }_{N L}}{\left(I_{\max }^{2}-I^{* 2}\right) \cdot I^{*}}=\frac{U_{\max } / \sqrt{3}-U^{*}{ }_{N L}}{2 I_{\max }^{3} /(3 \sqrt{3})}=\frac{3\left[U_{\max }-\sqrt{3} U^{*}{ }_{N L}\right]}{2 I_{\max }^{3}} ; \\
\beta_{0}=\frac{U_{\max }}{I_{\max }}-\frac{3\left[U_{\max }-\sqrt{3} U^{*}{ }_{N L}\right]}{2 I_{\max }^{3}} \cdot I_{\max }^{2}=\frac{3 \sqrt{3} U^{*}{ }_{N L}-U_{\max }}{2 I_{\max }} .
\end{gathered}
$$

Для прийняття рішення щодо неістотності зміни опору від струму ( $H_{0}$ гіпотеза) чи істотності ( $H_{1}$ гіпотеза) знаходять випадкову величину $t$ :

$$
t=\frac{\bar{R}\left(\theta^{0}\right)-\bar{R}\left(\theta_{0}^{0}\right)}{S_{\delta \hat{R}\left(\theta^{0}\right)}} \cdot \sqrt{n} .
$$

Перевірка за $t$-критерієм Стьюдента $3 n-1$ степенями свободи дає можливість прийняти із заданою достовірністю гіпотезу про лінійність чи нелінійність резистора.

Розглядаючи опір лінії електропередачі з мідного чи алюмінієвого дроту, прийнято на низьких частотах сигналу, до того ж на постійному струмі, представляти його безінерційним елементом з активним опором $R$. Але за достатньо великої густини струму він повільно нагрівається, змінюючи опір. Тоді зв'язок напруги і струму на ньому буде мати динамічний характер, що еквівалентно інерційності. Наприклад, у котушці індуктивності це призведе до зміни у часі ііі добротності, а при паралельному включенні конденсатора до зміни резонансної частоти коливального контура - загороджувального фільтра. За незмінної напруги $U$, зміна опору $R$ від квадрата струму призведе до зміни енергії $W_{e}$. На рис. 3 графічно показана енергія за час $T$ при незмінному опорі $W_{e}=U I(0) \cdot T$ як паралелограма і при змінному $W_{e}=U \int_{0}^{T} I(t) \cdot d t$ (фігура, що виділена жирними лініями).

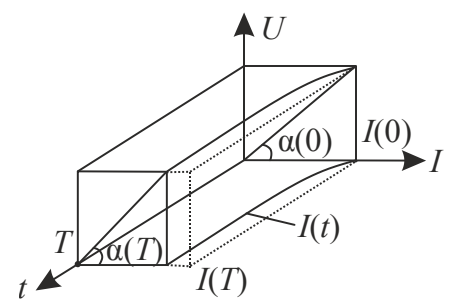

Рис. 3. Графічне відображення втрат електроенергії в проводах унаслідок їх поступового нагрівання струмом, де $\operatorname{tg} \alpha(0)=R(0), \operatorname{tg} \alpha(T)=R(T)$ 
Аналіз фактичних значень показника успішності і технологічності за умови використання нових методик до проведення лабораторних досліджень

Статистичний аналіз експериментальних даних з 2 курсів для навчальних груп без використання нових методик показав, що діапазон зміни значень локального критерію $Q_{U s p}$ знаходиться в інтервалі від 0,048 до 1. Різниця між мінімальним і максимальним фактичними значеннями показника успішності для 2 курсів склала 0,952. Гістограма емпіричного розподілу фактичних значень показників успішності представлена на рис. 4.
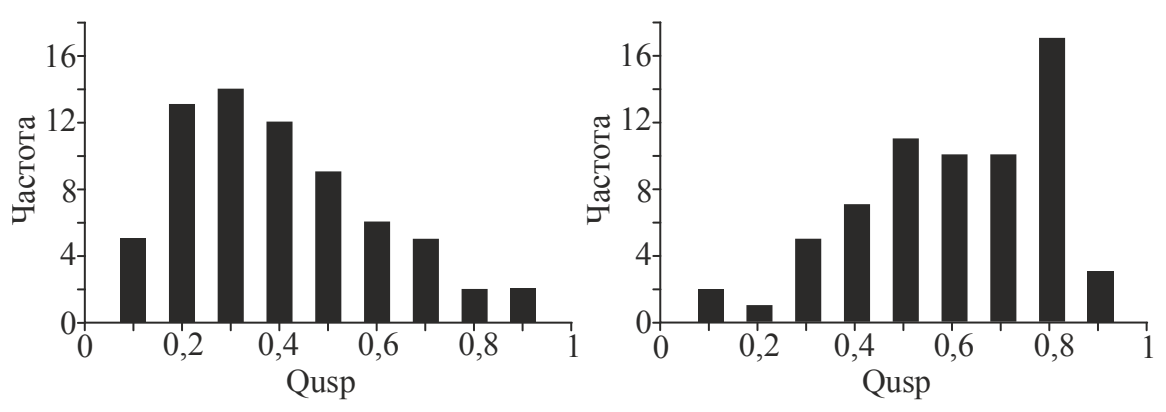

Рис. 4. Гістограма значень показника успішності без використання (зліва) та із використанням (праворуч) системного підходу

Статистичний аналіз експериментальних даних з 2 курсів для навчальних груп 3 використання нових методик показав, що діапазон зміни значень локального критерію $Q_{U s p}$ знаходиться в інтервалі від 0,084 до 1. Різниця між мінімальним і максимальним фактичними значеннями показника успішності для 2 курсів склала 0,916 .

3 аналізу гістограм можна стверджувати, що отримано підвищення рівня успішності при застосуванні системного підходу.

Статистичний аналіз фактичних значень показника технологічності 3 2 курсів для навчальних груп без використання нових методик показав, що значення змінюються в діапазоні від 0,014 до 0,52 . Різниця між мінімальним $\mathrm{i}$ максимальним фактичними значеннями показника склала 0,506 .
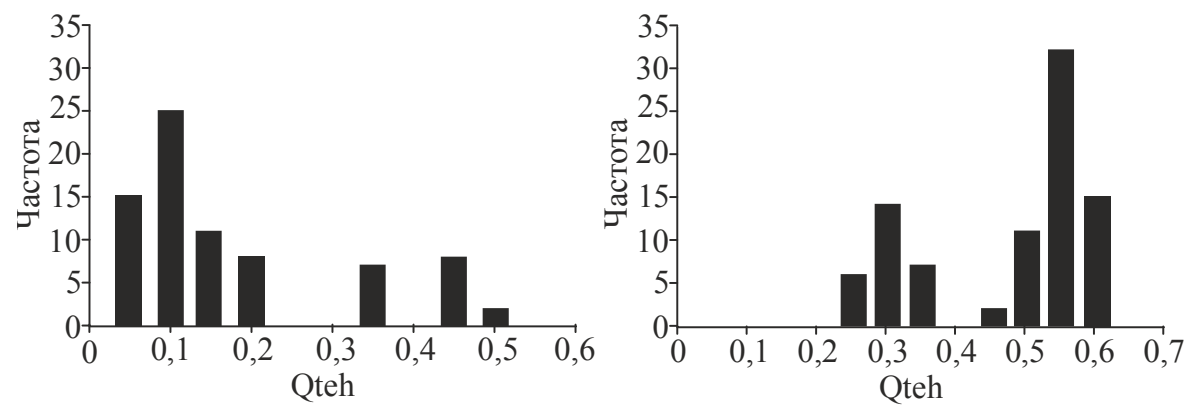

Рис. 5. Гістограма значень показника технологічності без використання (зліва) та із використанням (праворуч) системного підходу 
Згідно з рис. 5 для фактичних значень показника технологічності спостерігається тенденція до низьких значень коефіцієнтів технологічності $k^{T}$. Дана ситуація обумовлена переважно ручною обробкою результатів навчання в ході безпосередньої взаємодії зі студентами. У табл. 1 представлені експериментальні дані з курсу для розрахунку показника технологічності, для якого отримано значення $Q_{\text {Teh }}=0,087$.

Таблиия 1.

\begin{tabular}{|c|c|c|c|c|c|c|c|c|c|c|}
\cline { 2 - 13 } \multicolumn{1}{c|}{} & \multicolumn{4}{c|}{$\begin{array}{c}\text { без використанням } \\
\text { системного } \\
\text { підходу }\end{array}$} & \multicolumn{5}{c|}{$\begin{array}{c}\text { 3 використанням } \\
\text { системного } \\
\text { підходу }\end{array}$} \\
\hline робота & 1 & 2 & 3 & 4 & 5 & 1 & 2 & 3 & 4 & 5 \\
\hline показник & 4,5 & 4,5 & 4 & 4 & 3 & 6,5 & 7 & 7,5 & 7,5 & 7,5 \\
\hline$\alpha$ & 2 & 2 & 2 & 2 & 2 & 6 & 8 & 8 & 8 & 8 \\
\hline технологічність & 2 & 0,2 & 0,2 & 0,2 & 0,2 & 0,6 & 0,8 & 0,8 & 0,8 & 0,8 \\
\hline$k^{T}$ & 0,2 & 0,2 &
\end{tabular}

Статистичний аналіз фактичних значень показника технологічності 3 2 курсів для навчальних груп з використання нових методик показав, що значення змінюються в діапазоні від 0,318 до 0,6 . Різниця між мінімальним $\mathrm{i}$ максимальним фактичними значеннями показника склала 0,282 .

У табл.1 представлені експериментальні дані з курсу із використанням системного підходу, для якого отримано більш високе значення показника технологічності $Q_{\text {Teh }}=0,343$. Більш високий рівень технологічності обумовлений тим, що в 4 роботах 35 переважно автоматизована обробка, а рівень засвоєння завдання $\alpha$ знаходиться в межах від 5,3 до 7,5. Оскільки середнє $\alpha$ дорівнює 6,76, то можна стверджувати, що отримано підвищення рівня засвоєння даного курсу.

\section{Висновок}

Існуюча матеріальна база лабораторних робіт з електротехнічних дисциплін, доповнена ЕОМ, дає можливість, користуючись методикою, побудованою на основі системного підходу, суттєво модернізувати застарілі підходи до лабораторних робіт, зробити їх дійсно цікавими й корисними у формуванні у студентів навичок щодо наукових досліджень і більш точних інженерних розрахунків.

На прикладі лабораторної роботи, показано доцільність підходу, що є методично кориснішим, направленим на засвоєння навичок наукової діяльності та більш відповідальним (точним, акуратним) в інженерній діяльності.

За рахунок ефективних методик планування експерименту й оптимальної обробки його результатів на ЕОМ із сучасними пакетами прикладних програм для обробці даних експерименту, алгоритмами оптимального оцінювання, фільтрації збурень та ідентифікації, отримані математичні моделі дають змогу дослідити, на порядок швидше і глибше, різноманітні режими роботи об'єкта. 


\section{Література}

1. Данченко А.Л. Разработка комплексного критерия качества образовательных ресурсов / А. Л. Данченко, В. А. Ульшин // Вісник СНУ ім. В. Даля. — 2012. — № 4(175). C. $117-122$.

2. Advanced Distributed Learning [Electronic resource] / Advanced Distributed Learning. USA. - 2010. — Access mode : http://www.adlnet.gov/Pages/.

3. Самсонов В.В. Системний підхід до розробки моделі керування процесом навчання / В.В. Самсонов, А.М. Сільвестров, О.В.Скринник // Наукові праці Національного університету харчових технологій. — Київ : НУХТ, 2010. — № 33. - С. $84-87$.

4. Беспалько В.П. Основы теории педагогических систем. - Воронеж: Изд-во Воронеж. ун-та, 1977. - С. 303. 